\title{
Tumor necrosis factor-inducible gene 6 promotes liver regeneration in mice with acute liver injury
}

\author{
Sihyung Wang ${ }^{1}$, Ji-Seon Lee ${ }^{3}$, Jeongeun Hyun ${ }^{1}$, Jieun Kim ${ }^{1}$, Seung $\cup \mathrm{Kim}^{4}$, Hyuk-Jin $\mathrm{Cha}^{3^{*}}$ and Youngmi Jung ${ }^{1,2^{*}}$
}

\begin{abstract}
Introduction: Tumor necrosis factor-inducible gene 6 protein (TSG-6), one of the cytokines released by human mesenchymal stem/stromal cells (hMSC), has an anti-inflammatory effect and alleviates several pathological conditions; however, the hepatoprotective potential of TSG-6 remains unclear. We investigated whether TSG-6 promoted liver regeneration in acute liver failure.
\end{abstract}

Methods: The immortalized hMSC (B10) constitutively over-expressing TSG-6 or empty plasmid (NC: Negative Control) were established, and either TSG-6 or NC-conditioned medium (CM) was intraperitoneally injected into mice with acute liver damage caused by $\mathrm{CCl}_{4}$. Mice were sacrificed at 3 days post-CM treatment.

Results: Higher expression and the immunosuppressive activity of TSG-6 were observed in CM from TSG-6-hMSC. The obvious histomorphological liver injury and increased level of liver enzymes were shown in $\mathrm{CCl}_{4}$-treated mice with or without NC-CM, whereas those observations were markedly ameliorated in TSG-6-CM-treated mice with CCl 4 . Ki67-positive hepatocytic cells were accumulated in the liver of the $\mathrm{CCl}_{4}+$ TSG-6 group. RNA analysis showed the decrease in both of inflammation markers, tnfa, il-1 $\beta$, cxcl1 and cxcl2, and fibrotic markers, tgf- $\beta 1$, a-sma and collagen $\alpha 1$, in the $\mathrm{CCl}_{4}+\mathrm{TSG}-6$ group, compared to the $\mathrm{CCl}_{4}$ or the $\mathrm{CCl}_{4}+\mathrm{NC}$ group. Protein analysis confirmed the lower expression of TGF- $\beta 1$ and a-SMA in the $\mathrm{CCl}_{4}+\mathrm{TSG}_{-} 6$ than the $\mathrm{CCl}_{4}$ or the $\mathrm{CCl}_{4}+\mathrm{NC}$ group. Immunostaining for a-SMA also revealed the accumulation of the activated hepatic stellate cells in the livers of mice in the $\mathrm{CCl}_{4}$ and $\mathrm{CCl}_{4}+\mathrm{NC}$ groups, but not in the livers of mice from the CCl + TSG-6 group. The cultured LX2 cells, human hepatic stellate cell line, in TSG-6-CM showed the reduced expression of fibrotic markers, tgf- $\beta 1$, vimentin and collagen a1, whereas the addition of the TSG-6 antibody neutralized the inhibitory effect of TSG-6 on the activation of LX2 cells. In addition, cytoplasmic lipid drops, the marker of inactivated hepatic stellate cell, were detected in TSG-6-CM-cultured LX2 cells, only. The suppressed TSG-6 activity by TSG-6 antibody attenuated the restoration process in livers of TSG-6-CM-treated mice with $\mathrm{CCl}_{4}$.

Conclusions: These results demonstrated that TSG-6 contributed to the liver regeneration by suppressing the activation of hepatic stellate cells in $\mathrm{CCl}_{4}$-treated mice, suggesting the therapeutic potential of TSG-6 for acute liver failure.

\section{Introduction}

Acute liver failure and chronic liver disease are lifethreatening diseases for which liver transplantation is the only permanent remedy. However, the number of available organs from donors is vastly insufficient for the number of patients requiring such procedures. Even if transplant patients receive a whole liver transplantation, several post-transplant complications may arise, such as immune rejection response and death of the donor or

\footnotetext{
* Correspondence: hjcha@sogang.ac.kr; y.jung@pusan.ac.kr

${ }^{3}$ Department of Life Science, Sogang University, Seoul 121-742, Korea 'Department of Intergrated Biological Science, Pusan National University, 63-2 Pusandaehak-ro, Kumjeong-gu, Pusan 609-735, Korea

Full list of author information is available at the end of the article
}

recipient in worst-case scenarios [1]. Therefore, extensive studies are being conducted to develop new treatments for liver diseases, and stem cell based therapy has been suggested as an alternative treatment strategy for patients who suffer from various hepatic diseases [2].

Mesenchymal stem cells (MSCs) found in most adult and postnatal organs are capable of self-renewing and differentiating into several lineages of cells, including hepatocytes $[3,4]$. This differentiation potential of MSCs into hepatocytes provides new and promising therapeutics for patients with liver disease. These therapeutic effects of MSCs in the treatment of liver disease have been reported both in animal and clinical studies [5]. In those studies, MSCs were shown to contribute to liver regeneration by secreting 
tropic and immunomodulatory molecules [6,7]. However, there are still a number of technical limitations or possible undesirable side effects associated with the therapeutic application of MSCs to patients with end-stage liver diseases [8]. In particular, engrafted MSCs can differentiate into not only hepatocytes but also myofibroblasts, a main source of collagen fiber in a fibrotic liver, depending on the timeframe of differentiation and route of MSC injection [9]. Hence, further characterization of MSCs may be critical for ensuring the safety of MSC-based cell therapy. The beneficial effect of MSC transplantation is based on autologous transplantation. However, it is difficult to try MSC transplantation with patients with end-stage liver disease [9]. Although allogeneic stem cell transplantation might be more effective for these patients, it also brings several obstacles, such as immune rejection or engraftment of viruscarrying MSCs [1]. The paracrine effect, which results from biologically active soluble factors secreted from human MSCs (hMSCs), such as angiopoietin-1, interleukin10, keratinocyte growth factor, and so on, has been shown to be therapeutically valid in both animal and clinical studies $[10,11]$. Since many kinds of tropic and immunomodulatory factors secreted from MSCs are also known to create a favorable micro-environment for liver regeneration [9], it is necessary to identify and characterize such biologically active soluble factors.

Tumor necrosis factor-inducible gene 6 protein (TSG-6), a $35 \mathrm{kDa}$ glycoprotein [12], was identified as an inflammatory factor as its expression increased in response to inflammatory mediators [13]. However, upregulated TSG-6 during the inflammatory process has been shown to contribute to modulate the inflammatory response in adverse [13]. Recent studies demonstrate that TSG-6 is identified as an important immune modulator secreted from hMSCs and shown to be responsible for hMSCs' therapeutic effects, such as improvement of cardiac function, peritonitis and wound healing [14]. However, these associations of TSG-6 with response in the liver are unknown.

Liver inflammation occurs in response to damage [15]. Liver injuries stimulate the repair response, such as proliferation of hepatocytes and inflammation, and a successful repair response reconstitutes a functional liver [16]. However, continued damage perpetuates injury and promotes progressive fibrogenesis [16]. Liver inflammation also accelerates fibrosis [17]. Several inflammatory factors, such as tumor necrosis factor (TNF- $\alpha$ ) and interleukin (Il) $-1 \beta$, and Il-6, secreted by inflammatory cells are involved in the recruitment of circulating macrophages into the liver and the transition of hepatic stellate cells into myofibroblasts [18]. This progressive fibrogenesis ends with death from cirrhosis and/or liver cancer [19]. Thus, the modulation of liver inflammation in this setting is a key target for reducing fibrosis. For this reason, we hypothesized that TSG-6 could influence liver regeneration by reducing inflammation and fibrosis because TSG-6 exerts an antiinflammatory effect. To prove our hypothesis, we made immortalized hMSCs stably expressing TSG-6. Due to constant secretion of TSG- 6 from hMSCs in the conditioned medium (CM), TSG-6-rich CM could be readily applied to mice with acute liver injury caused by $\mathrm{CCl}_{4}$. Our results showed that TSG- 6 promoted liver regeneration by decreasing fibrosis.

\section{Methods}

\section{Generation of hMSCs stably expressing TSG-6}

We sub-cloned P/I-TSG-6 (kindly provided by Dr. TaeHee Lee in Yonsei Univ.) into a CSII-EF-MCS vector. hMSCs stably expressing TSG-6, were generated as previously reported [20]. In detail, each viral plasmid $(3 \mu \mathrm{g})$ (CSII-EF-MCS and CSII-EF-TSG-6) was transfected into 293FT cells with pLP1, pLP2, pLP/VSVG, using lipofectamine 2000 (cat. \#11668-027, Life Technologies, Inc. Grand Island, NY, USA). After 48 hours, the culture media containing the lenti-viruses were collected from the transfected 293FT cells. Virus medium was filtered (0.45 $\mu \mathrm{m}$ filter, EMD Millipore, Billerica, MA, USA) and then treated to hMSCs for an additional 24 hours in the presence of $4 \mu \mathrm{g} / \mathrm{ml}$ of polybrene (Sigma-Aldrich, St. Louis, MO, USA). B10-hMSCs were maintained as described previously [21].

\section{Preparation of conditioned media}

For preparation of $\mathrm{CM}$, cells were seeded at more than 90\% confluence. The next day, cells were washed with PBS twice, changed to $0.2 \%$ fetal bovine serum (FBS)containing media and incubated for another three days. $\mathrm{CM}$ were further concentrated with YM-10 (Millipore, Cat. No. 4205).

\section{Immune suppression assay}

Splenocytes, $1.5 \times 10^{6}$ per well (24-well) (freshly isolated from C57BL6 female mice as described previously [22]), were cultured with or without $\mathrm{CM}$ supplement for three days. To stimulate $\mathrm{T}$ cells, $1 \mu \mathrm{g} / \mathrm{ml}$ of anti-CD3e (2C11) (BD Pharmingen, San Jose, CA, USA) was added. Cells were fluorescence labeled with carboxyfluorescein succinimidyl ester (CFSE) and then proliferation after activation was determined by flow cytometry (BD, FACS Calibur $\left.{ }^{\mathrm{Tm}}\right)$.

\section{Animal studies}

Six-week old male C57BL6 mice were purchased from Hyochang (Dae-gu, Korea), fed with a normal diet, watered, and housed with a 12 hour light-dark cycle. In vivo experiments were performed as previously described. Mice were seven weeks of age and weighed an average of $21 \mathrm{~g}$ at the start of the experiments. To induce acute liver injury, mice received $\mathrm{CCl}_{4}(1.0 \mathrm{mg} / \mathrm{kg}$ body weight) $(\mathrm{n}=15)$ intraperitoneally twice for one week as previously described [23]. As 
controls, animals received the same volume of corn oil vehicle (CTRL) $(n=4)$ intraperitoneally. Those mice were then injected i.p. with $0.5 \mathrm{ml}$ CM from TSG- 6 overexpressing MSCs (TSG-6) $(\mathrm{n}=6)$, or empty plasmid-carrying MSCs (NC; negative control) $(n=5)$ at day 8 , and sacrificed at day 3 following the medium treatment (Figure 1A). To examine the specificity of TSG-6 for liver, TSG-6-CM was incubated with TSG-6 antibody $(10 \mu \mathrm{g} / \mathrm{ml}$ ) (Santa Cruz Biotechnology, Santa Cruz, CA, USA) or control immunoglobulin G (IgG) $(10 \mu \mathrm{g} / \mathrm{ml})$ (Sigma-Aldrich) for one hour at room temperature, and $0.5 \mathrm{ml}$ of these CMs was injected into $\mathrm{CCl}_{4}$-treated mice (TSG-6-CM + TSG-6 antibody group: $n=5$ / TSG-6-CM + IgG group: $n=5$ ) (Figure $1 B$ ).

Animal care and surgical procedures were approved by the Pusan National University Institutional Animal Care and Use Committee and carried out in accordance with the provisions of the National Institutes of Health Guide for the Care and Use of Laboratory Animals.

\section{Measurement of AST/ALT}

Serum aspartate aminotransferase (AST) and alanine aminotransferase (ALT) were measured using Chemi Lab GOT/GPT (IVD Lab Co., Korea) according to the manufacturer's instructions.

\section{Liver histology and immunohistochemistry}

Liver specimens were fixed in $10 \%$ neutral buffered formalin, embedded in paraffin and cut into $4 \mu \mathrm{m}$ sections. Specimens were dewaxed, hydrated, and stained in the usual manner with standard hematoxylin and eosin ( $\mathrm{H} \& \mathrm{E})$ to examine morphology. For immunohistochemistry (IHC), sections were incubated for 10 minutes in 3\% hydrogen peroxide to block endogenous peroxidase. Antigen retrieval was performed by heating in $10 \mathrm{mM}$ sodium citrate buffer ( $\mathrm{pH}$ 6.0) or incubating with pepsin for 10 minutes. After washing with TBS, sections were treated with Dako protein block (X9090; Dako Envision, Carpinteria, CA) for $30 \mathrm{mi}-$ nutes and incubated with primary antibody Ki67 (NCL-
Ki67, Novocastra, Leica Microsystems, Newcastle, Upon Tyne, UK), pancytokeratin (PanCK) (Z0622; Dako), Sox9 (AB5535; Millipore), or $\alpha$-Sma (ab5694; Abcam, Cambridge, Massachusetts, USA), at $4^{\circ} \mathrm{C}$ overnight. Other sections were also incubated at $4^{\circ} \mathrm{C}$ overnight in non-immune sera to demonstrate staining specificity. Polymer horseradish peroxidase (HRP) anti-rabbit (K 4003; Dako) or anti-mouse (K 4001; Dako) was used as secondary antinody. 3,3' Diaminobenzidine (DAB) was employed in the detection procedure.

\section{Cell counting}

To quantify the number of Ki67-positive cells, 10 central vein $(\mathrm{CV})$ areas were randomly selected per section at $\times$ 40 magnification for each mouse. CV chosen for analysis ranged from 90 to $150 \mu \mathrm{m}$. The Ki67-positive cells were quantified by counting the total number of Ki67-positive cells per field.

\section{Quantitative real-time PCR}

Total RNA which had been stored at $-80^{\circ} \mathrm{C}$ was extracted with TRIZOL ${ }^{\mathrm{T}}$ (Ambion $^{\circ}$ by Life Technologies). After assuring RNA quality and concentration, gene expression was evaluated by QRT-PCR analysis. mRNAs were quantified by real-time RT-PCR according to the manufacturer's specifications (Eppendorf, Mastercycler Real-TIme PCR, Effendorf Korea Ltd., Seoul, Korea). The sequences of primers for mice are listed in Table 1. Samples were analyzed in duplicate according to the $\Delta \Delta \mathrm{Ct}$ method. All PCR products were directly sequenced for genetic confirmation in Macrogen Inc (Korea).

\section{Western blot assay}

Total protein was extracted from freeze-clamped liver tissue samples that had been stored at $-80^{\circ} \mathrm{C}$. Whole tissues were homogenized in RIPA (78510; Thermo, Rockford, IL) supplemented with protease inhibitors (Complete Mini 11 836153 001; Roche, Indianapolis, IN). Equal amounts of
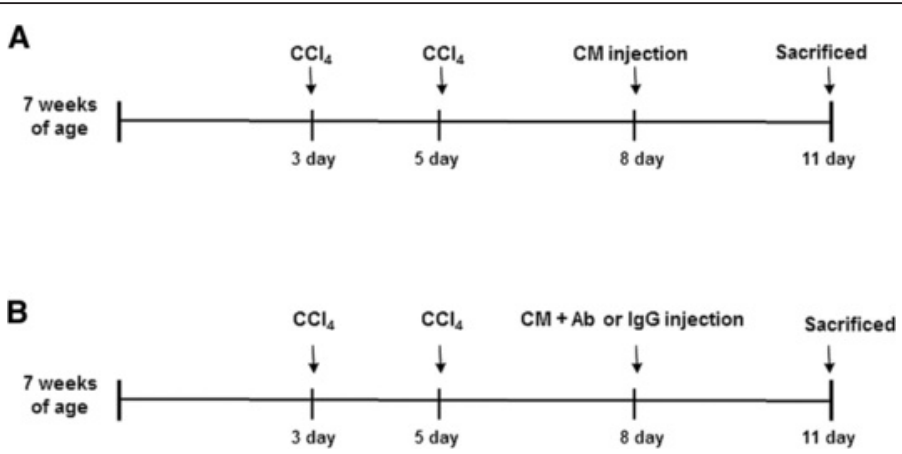

Figure 1 Design of mouse experimental model. (A) After being i.p. injected with $\mathrm{CCl}_{4}$ or corn oil (CTRL) twice for one week, mice were treated with NC-CM or TSG-6-CM, one time at eight days. These mice were sacrificed at 11 days. (B) $\mathrm{CCl}_{4}$-treated mice were injected with the neutralized TSG-6-CM by TSG-6 antibody or the TSG-6-CM + lgG antibody. These mice were also sacrificed at 11 days. CM, conditioned medium; CTRL, control; IgG, immunoglobulin G; i.p., intraperitoneally; NC, negative control; TSG-6, tumor necrosis factor-inducible gene 6 protein. 
Table 1 Sequences of primers used for QRT-PCR

\begin{tabular}{|c|c|c|}
\hline \multicolumn{3}{|l|}{ Mouse } \\
\hline Gene & Forward sequence & Reverse sequence \\
\hline$g 6 p c$ & TCCTCCTCAGCCTATGTCTGCATTC & GAGAGAAGAATCCTGGGTCTCCTTG \\
\hline $\operatorname{tg} f-\beta 1$ & TTGCCCTCTACAACCAACACAA & GGCTTGCGACCCACGTAGTA \\
\hline a-sma & AAACAGGAATACGACGAAG & CAGGAATGATITCCAAAGGA \\
\hline collagen a1 & GAGCGGAGAGTACTGGATCG & GCTTCTITCCTTGGGGTTC \\
\hline tnf-a & TCGTAGCAAACCACCAAGTG & ATATAGCAAATCGGCTGACG \\
\hline $\mathrm{il}-1 \beta$ & ACTCCTTAGTCCTCGGCCA & TGGTITCTTGTGACCCTGAGC \\
\hline cxcl1 & CCCAAACCGAAGTCATAGCC & TCAGAAGCCAGCGTTCACC \\
\hline $\mathrm{Cxcl} 2$ & GCCCAGACAGAAGTCATAGCC & TTCTCTTGGTTCTTCCGTTGA \\
\hline $9 s$ & GACTCCGGAACAAACGTGAGG & СTTCATCTTGCCCTCGTCCA \\
\hline \multicolumn{3}{|l|}{ Rat } \\
\hline Gene & Forward Sequence & Reverse Sequence \\
\hline tsg-6 & AGTGATGCGTCCGTCACAGCC & AGATGGCTAAACCGTCCAGCTAAGA \\
\hline $9 \mathrm{~s}$ & GACTCCGGAACAAACGTGAGGT & CTTCATCTTGCCCTCGTCCA \\
\hline \multicolumn{3}{|l|}{ Human } \\
\hline Gene & Forward sequence & Reverse sequence \\
\hline $\operatorname{tg} f-\beta 1$ & TTGACTGAGTTGCGATAATGTT & GGGAAATTGCTCGACGAT \\
\hline vimentin & CGAAAACACCCTGCAATCTT & GTGAGGTCAGGCTTGGAAAC \\
\hline collagen al & CAGATCACGTCATCGCACAA & TGTGAGGCCACGCATGAG \\
\hline $9 s$ & GACTCCGGAACAAACGTGAGGT & CTTCATCTTGCCCTCGTCCA \\
\hline
\end{tabular}

total protein $(120 \mu \mathrm{g})$ were fractionated by polyacrylamide gel electrophoresis and transferred to polyvinylidene difluoride (PVDF) membranes. Primary antibodies against TGF- $\beta$ (3711S; Cell Signaling) and $\alpha$-Sma (A5228-200UL; Sigma-Aldrich) were used in this experiment. Membranes were developed by chemiluminescence (ATTO Corporation, Tokyo, Japan). The blots that were obtained from three independent experiments were scanned and a region of interest (ROI) around the band of interest was defined. Band intensities were calculated by using the CS analyzer 2.0 program (ATTO Corporation).

\section{Cell experiments}

The human hepatic stellate cell line LX2, a wellcharacterized cell line derived from human hepatic stellate cells [24], B10-NC and B10-TSG-6 were cultured at a density of $2 \times 10^{6}$ in Minimum Essential Medium alpha (MEM $\alpha$, Gibco, Life Technologies) supplemented with 10\% FBS (Gibco, Life Technologies, Grand Island, $\mathrm{NY}$ ) and $1 \mathrm{X}$ antibiotics at $37^{\circ} \mathrm{C}$ in a humidified atmosphere containing 5\% CO2. LX2 was a generous gift from Won-il Jung (Korea Advanced Institute of Science and Technology). When B10-NC or B10-TSG-6 cells were $70 \%$ to $80 \%$ confluent, CM of these cells were collected to treat LX2. For biochemical analysis of gene expression changes, LX2 at $70 \%$ to $80 \%$ confluence were starved in medium containing no FBS for six hours. Activation of
LX2 was verified by examining the expression of profibrotic signaling genes at 24 and 48 hours after addition of FBS. Based on the gene expression data, we considered LX2 as fully activated cells at 48 hours (data not shown). Fully activated LX2 was cultured in LX2 cell medium, B10-NC-CM or TSG-6-CM. In addition, those cells cultured in TSG-6-CM were treated with TSG-6 antibody $(10 \mu \mathrm{g} / \mathrm{ml})$ or control IgG $(10 \mu \mathrm{g} / \mathrm{ml})$. These experiments were repeated three times [25].

\section{Statistical analysis}

Results are expressed as the mean \pm standard deviation (SD). Statistical differences were determined by Student's t-test or one-way analysis of variance (ANOVA) using the SPSS statistics 20, followed by Scheffe' post hoc test. Pvalues $<0.05$ were considered to be statistically significant.

\section{Results}

Generation of TSG-6-overrexpressing MSCs

To investigate the effect of TSG-6 in liver injury, we generate hMSCs stably expressing TSG-6 based on immortalized fetal bone marrow hMSCs (B10) [21], using a lentivirus delivery system. The stable expression of TSG-6 in hMSCs was confirmed by a higher expression level of TSG- 6 mRNA (Figure 2A) and protein (Figure 2B) in TSG-6-hMSCs. More importantly, a detectable level of TSG-6 protein was also found in the CM from TSG-6-hMSCs (Figure 2B, lower 
A

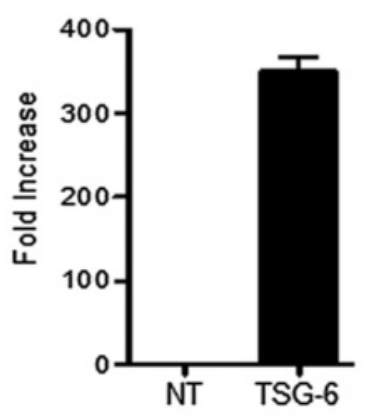

C

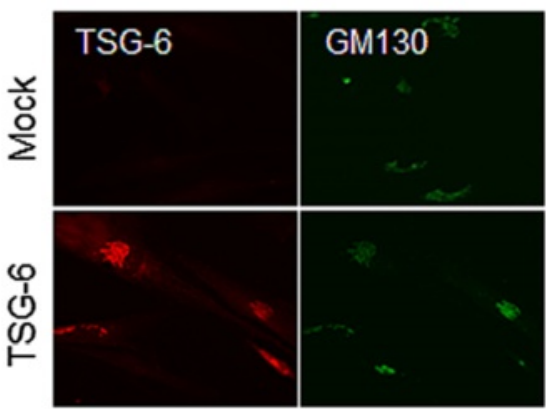

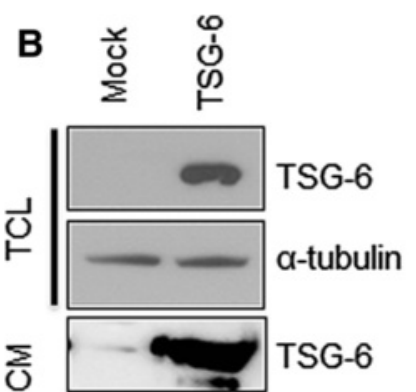

D

Control medium
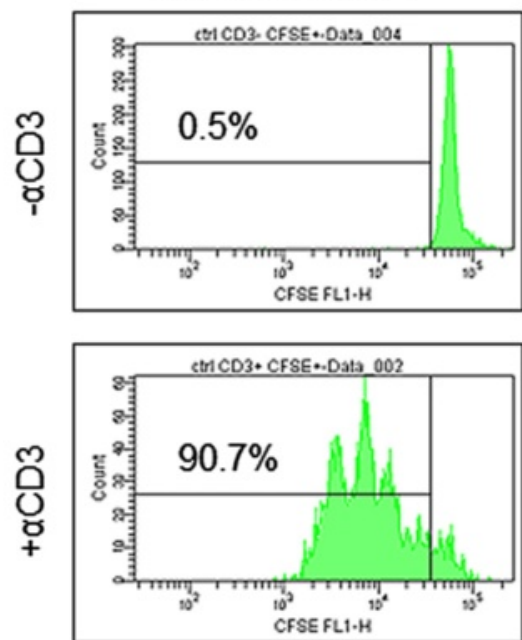

B10(MSC) CM
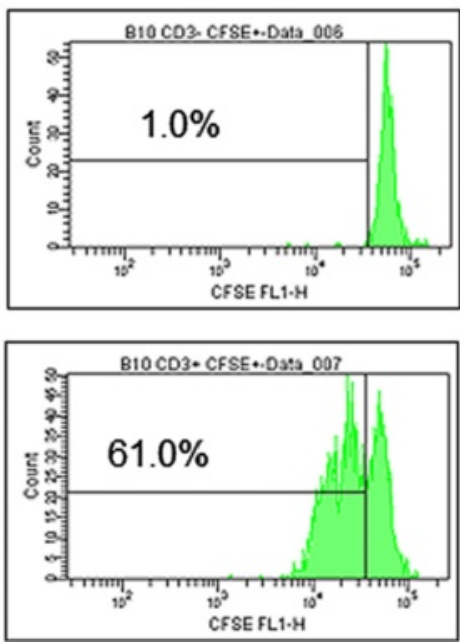

TSG-6 B10(MSC) CM
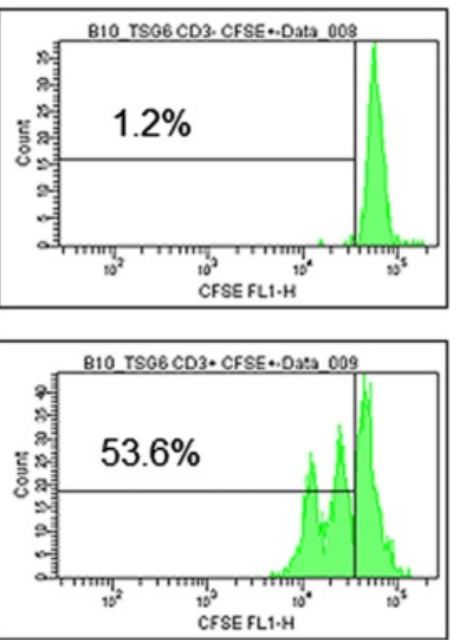

Figure 2 Production of MSC overexpressing TSG-6. (A) The mRNA level of TSG-6 in CSII-EF-MCS- and CSII-EF-TSG-6-expressing hMSC cells was determined via real-time PCR. (B) TSG-6 stable transfection to hMSCs was confirmed by immunoblotting for Wip1 (top panel). Equal protein loading was verified by a-tubulin immunoblotting (middle panel). Secretion of TSG-6 in hMSCs was confirmed in the conditioned media by immunoblotting for TSG-6 (bottom panel). (C) TSG-6 expression in TSG-6-hMSC was validated by immunostaining with anti-TSG-6 antibody (left panel, TSG-6). GM130 was counterstained as a Golgi complex marker (middle panel, GM130). DAPI was used for nuclear counterstaining (right panel, DAPI). (D) CD4 ${ }^{+}$T cells from mouse splenocytes were cultured in the presence of CD3 antibody $(1 \mu \mathrm{g} / \mathrm{ml}$ of a-CD3). T cells proliferation was determined by FACS analysis after CFSE staining. CM either from hMSCs (B10) or TSG-6-hMSCs were incubated for three days in the presence of CD3 antibody. Culture medium for hMSCs was used as the control medium. CFSE, carboxyfluorescein succinimidyl ester; CM, conditioned medium; DAPI, 4',6-diamidino-2-phenylindole; FACS, fluorescence activated cell sorting; hMSCs, human mesenchymal stem cells; MSCs, mesenchymal stem cells; TSG-6, tumor necrosis factor-inducible gene 6 protein.

panel). Given that TSG-6, a glycoprotein is processed in the Golgi complex, a distinct signal from the Golgi complex (determined by GM130, a typical Golgi marker) in TSG-6-
hMSCs was clearly observed (Figure $2 \mathrm{C}$ ). To examine the immune-modulatory activity of TSG-6 secreted from TSG6-hMSCs, splenocytes freshly isolated from the mouse 
spleen were treated with CM from hMSCs (B10) or TSG-6hMSCs (TSG-6 B10). While activated CD4 ${ }^{+}$T cells by CD3 antibody underwent active proliferation, proliferation of $\mathrm{CD}^{+} \mathrm{T}$ cells was markedly reduced following treatment with CM from either hMSC or TSG-6-hMSCs, compared to control medium even after CD3 stimulation. Of interest, CM from TSG-6-hMSCs appeared to be more effective in suppressing $\mathrm{T}$ cell proliferation (Figure 2D).

\section{TSG-6 attenuates liver injury}

To examine whether TSG-6 influenced liver regeneration, mice were treated with $\mathrm{CCl}_{4}$ to induce acute liver injury and i.p. injected with TSG-6-rich CM (TSG-6-CM) $\left(\mathrm{CCl}_{4}+\right.$
TSG-6-CM: TSG-6 group) or TSG-6-poor CM (NC$\mathrm{CM})\left(\mathrm{CCl}_{4}+\mathrm{NC}-\mathrm{CM}\right.$ : NC group). Liver sections from those mice were examined for the effect of TSG-6 using H \& E staining. $\mathrm{CCl}_{4}$-treated mice showed severe cytoplasmic vacuolation, microvesicular fatty changes, loss of cellular boundaries, infiltration of inflammatory cells around the central vein and in the portal areas, congestion in the sinusoids, and necrosis of the liver cells. Interestingly, those abnormal morphological changes were remarkably ameliorated and restored to almost normal morphology in the TSG- 6 group, compared to the $\mathrm{NC}$ and $\mathrm{CCl}_{4}$ groups (Figure 3A). The ratio of liver weight versus body weight (LW/BW) declined in mice in the $\mathrm{CCl}_{4}$ and $\mathrm{NC}$ groups

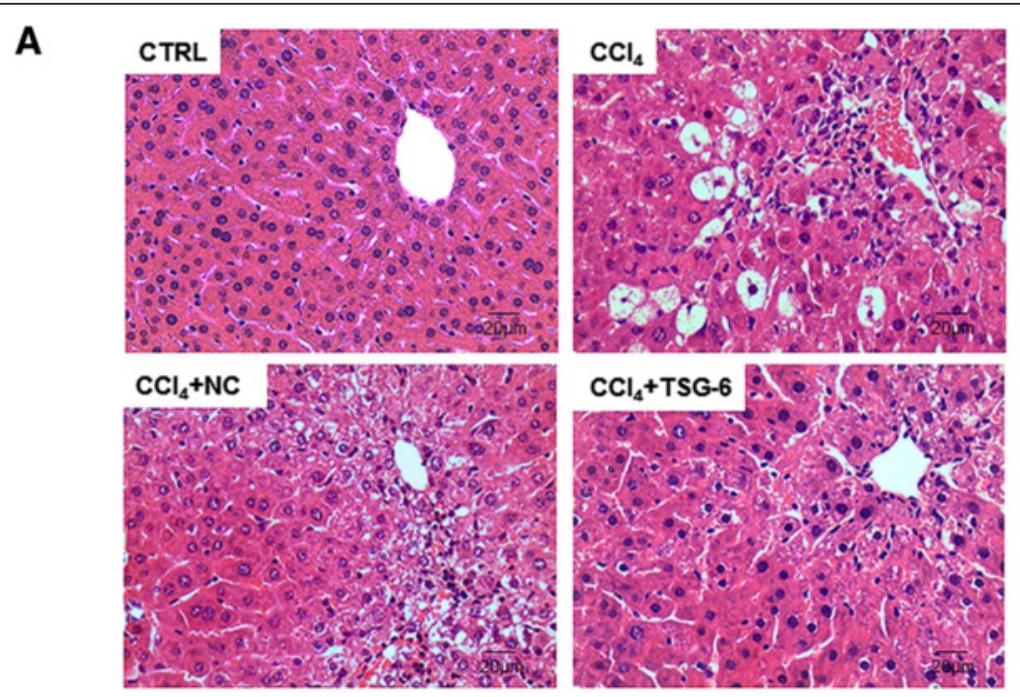

B
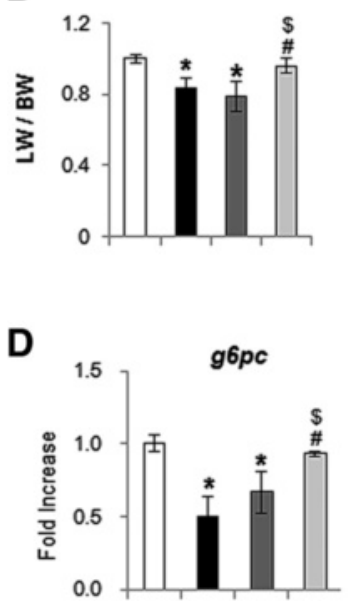

C
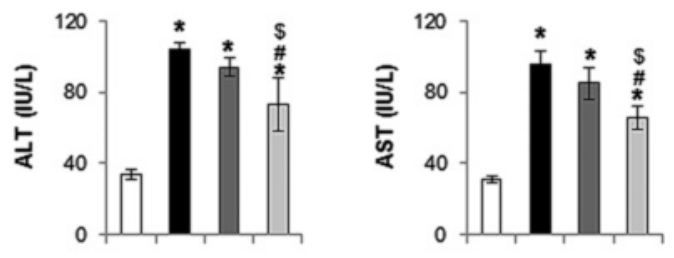

*: vS CTRL

\#: vs $\mathrm{CCl}_{4}$

\$: vs $\mathrm{CCl}_{4}+\mathrm{NC}$

Figure 3 Effects of TSG-6 on liver histomorphology and function in $\mathrm{CCl}_{4}$-treated mice. (A) $\mathrm{H}$ \& E staining shows the extensive cellular damage and infiltration of inflammatory cells in $\mathrm{CCl}_{4}$-treated mice with or without NC (negative control: mock transfected cell)-conditioned medium (CM). Those cellular injuries were reduced in $\mathrm{CCl}_{4}$ mice treated with TSG-6-CM (CCl + + TSG-6). The representative images are shown at $\times 40$ (CTRL: corn-oil-treated control mice/ $\mathrm{CCl}_{4}: \mathrm{CCl}_{4}$-treated mice/ $\mathrm{CCl}_{4}+\mathrm{NC}$ : $\mathrm{CCl}_{4}$-treated mice with NC-CM). (B) Relative liver weight / body weight of mice. (C) The values of AST and ALT are graphed. (D) QRT-PCR analysis for G6pc of liver mRNA from normal (CTRL), CCl , CCl $_{4}$ with NC-CM (NC) or TSG-6-CM (TSG-6) ( $\mathrm{n} \geq 4$ mice / group) (ANOVA, *P <0.05 versus CTRL, \#P< <0.05 versus $C_{C l}, \$ P<0.05$ versus $C_{4} C_{4}+N C-C M$ ). ALT, alanine aminotransferase; ANOVA, analysis of variance; AST, aspartate aminotransferase; G6pc, glucose-6-phosphatase; TSG-6, tumor necrosis factor-inducible gene 6 protein. 
$\left(\mathrm{CCl}_{4}: \quad 0.836 \pm 0.056, \quad \mathrm{NC}: 0.788 \pm 0.086\right.$, compared to control, $\left.{ }^{*} P<0.05\right)$, whereas there was no significant change of LW/BW between the control and TSG-6 groups (Figure $3 \mathrm{~B}$ ). In addition, $\mathrm{CCl}_{4}$-treated mice with or without NC-CM had elevated serum AST and ALT, whereas $\mathrm{CCl}_{4}$-treated mice with TSG-6-CM had alleviated AST (control-31.32 $\pm 1.74, \mathrm{CCl}_{4}-95.72 \pm 7.23, \mathrm{NC}-85.09 \pm 8.59$ and TSG-6-5.84 \pm 6.28 ) and ALT (control-33.95 $\pm 3.09, \mathrm{CCl}_{4}$ $104.52 \pm 3.09$, NC-94.33 \pm 4.79 , and TSG-6-73.25 \pm 15.03 ) (Figure 3C). Furthermore, the RNA level of glucose-6phosphatase (G6pc), which is known to be an essential enzyme for glycolysis, was similar between the control and TSG-6 groups (Figure 3D).

To determine if these changes in the liver repair process were associated with the hepatocyte proliferation, liver sections from CM-treated mice with $\mathrm{CCl}_{4}$ were stained for Ki67, a marker of S phase [26]. The injured livers of mice with or without NC-CM mainly had Ki67-positive hepatic stellate-looking cells, whereas livers of mice with TSG-6-CM largely contained Ki67-positive hepatocytic cells (Figure 4). Because liver damage leads to expansion of liver progenitors [26,27], it was further investigated whether reduced liver injuries influenced the proliferation of liver progenitors. As assessed by IHC for PanCK and Sox9, two different markers of liver progenitors [28-30], both the $\mathrm{CCl}_{4}$ and $\mathrm{NC}$ groups exhibited an expansion of hepatic progenitors compared to the control and TSG-6 groups (Figure 5). Therefore, these results suggested that TSG-6 promoted the repair process into the normal restoration of the liver by contributing to hepatocyte proliferation.

\section{Decreased hepatic fibrosis in TSG- 6 treated mice}

Because $\mathrm{CCl}_{4}$ is a well-known chemical that induces hepatocyte injury and inflammation, promoting collagen deposition, we examined whether TSG-6 might exert an anti-inflammatory effect, thereby decreasing fibrogenesis in this animal model. The expression of inflammation markers, such as tnf $\alpha$, il-1 $\beta$, cxcl1 and $\operatorname{cxcl} 2$, was significantly higher in the $\mathrm{CCl}_{4}$ and $\mathrm{NC}$ groups than in the TSG-6 group (Figure 6). The RNA expression of the fibrotic markers, tgf- $\beta$, $\alpha$-sma and collagen $\alpha 1$, was greatly

A
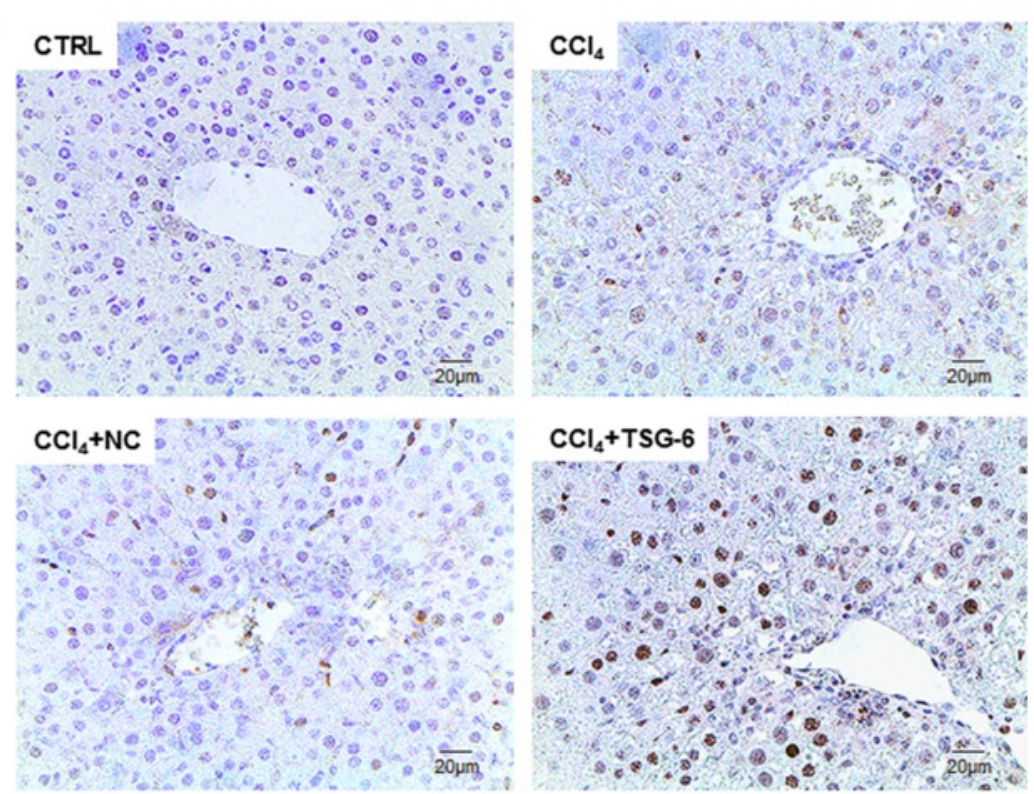

B

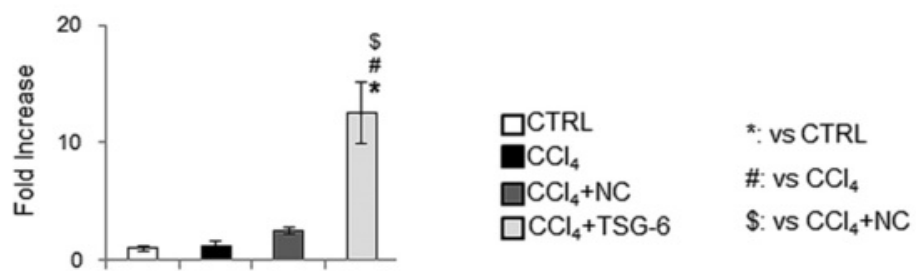

Figure 4 Expansion of Ki67-positive hepatocytic cells in liver of mice with $\mathrm{CCl}_{4}+\mathrm{TSG}-6$ treatment. (A) $1 \mathrm{HC}$ for Ki67 in liver sections from representative control, $\mathrm{CCl}_{4}, \mathrm{CCl}_{4}+\mathrm{NC}$, and $\mathrm{CCl}_{4}+\mathrm{TSG}-6$ mice $(\times 40)$. (B) Ki67-positive hepatocytes were counted and graphed (ANOVA, * $P<0.05$ versus $C T R L, \# P<0.05$ versus $C C_{4}, \$ P<0.05$ versus $\left.C C_{4}+N C-C M\right)$. ANOVA, analysis of variance; $C M$, conditioned medium; $C T R L$, Control; $I H C$, immunohistochemistry; NC, negative control; TSG-6, tumor necrosis factor-inducible gene 6 protein. 

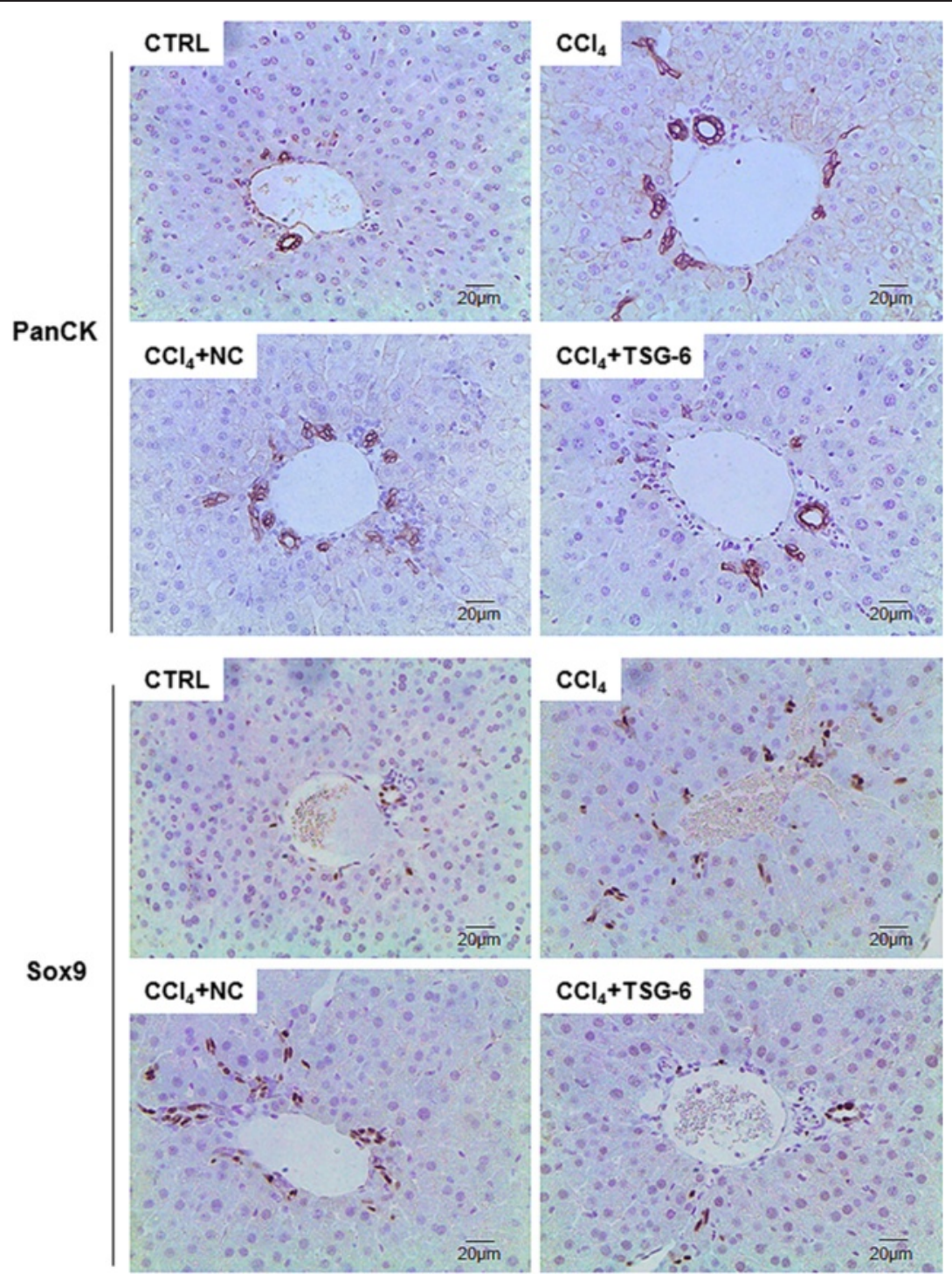

Figure 5 TSG-6 decreases the proliferation of hepatic progenitors in the liver damaged with $\mathbf{C C l}_{\mathbf{4}}$. $\mathrm{HC}$ for PanCK and Sox9 in liver sections from representative control, $\mathrm{CCl}_{4}, \mathrm{CCl}_{4}+\mathrm{NC}$, and $\mathrm{CCl}_{4}+\mathrm{TSG}-6$ mice ( $\left.\times 40\right)$. IHC, immunohistochemistry; NC, negative control; PanCK, pancytokeratin; TSG-6, tumor necrosis factor-inducible gene 6 protein.

upregulated in the $\mathrm{CCl}_{4}$ and $\mathrm{CCl}_{4}+\mathrm{NC}$-CM-treated livers, whereas those genes were downregulated in injured livers treated with TSG-6-CM (Figure 7A). In line with mRNA expression, the protein level of TGF- $\beta$ and $\alpha$-SMA decreased in the TSG- 6 treated group, showing the baseline TGF- $\beta$ and $\alpha$-SMA expression in healthy livers (Figure 7B, C). In addition, IHC staining for $\alpha$ SMA clearly showed that the accumulation of activated hepatic stellate cells in livers of the $\mathrm{CCl}_{4}$ and $\mathrm{NC}$ groups was reduced in the livers of the TSG-6 group (Figure 7D). Therefore, these results demonstrated that the TSG-6 attenuated both inflammation and the expansion of fibrous matrix in the injured liver.

\section{TSG-6 induced inactivation of hepatic stellate cells}

Fibrosis is the excessive accumulation of collagen and other extracellular matrix components, and the accumulated fibrotic tissues disarrange the liver constitution. A change in the hepatic structure induces hepatic dysfunction, leading to the death of the patient. Several types of cells, such as bone marrow-derived cells, circulating fibrocytes, and portal fibroblasts, are known to contribute to hepatic fibrosis by transitioning to myofibroblasts. Particularly, activated hepatic stellate cells are primary sources of myofibroblastic cells promoting fibrogenesis. Hence, we investigated whether TSG- 6 was involved in the activation of hepatic stellate cells because our data showed regressed fibrosis in the TSG-6 

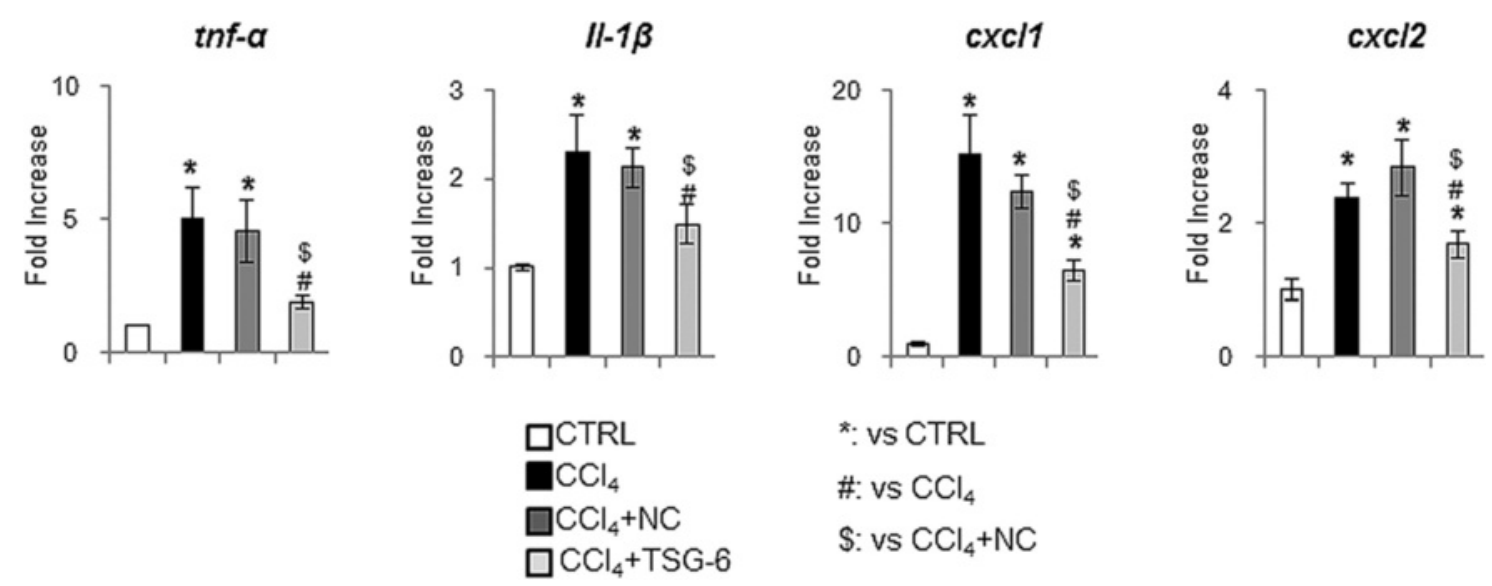

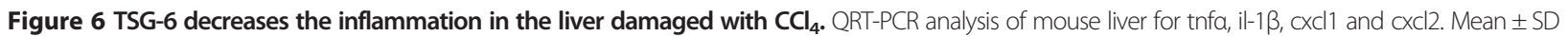
results are graphed ( $n \geq 4$ mice/group) (ANOVA, ${ }^{*} P<0.05$ versus $C T R L$, $\# P<0.05$ versus $C C l_{4}, \$ P<0.05$ versus $C C l_{4}+N C-C M$ ). ANOVA, analysis of variance; $C M$, conditioned medium. CTRL, control; NC, negative control; SD, standard deviation; TSG-6, tumor necrosis factor-inducible gene 6 protein.

treated group. LX2 cells cultured in TSG-6-CM showed decreased expression of activated markers of hepatic stellate cells, such as tgf- $\beta$, vimentin and collagen $\alpha 1$, whereas cells cultured in NC-CM or LX2 cell medium had greatly increased expression of those markers. In addition, neutralization of TSG- 6 by the TSG- 6 antibody effectively induced the expression of those markers in LX2 cells (Figure 8A). Oil Red O staining showed cytoplasmic lipid droplets, the morphologic hallmark of inactivated hepatic stellate cells, in the LX2 cells cultured in TSG-6$\mathrm{CM}$, whereas those lipid droplets were not seen in cells cultured in NC-CM or LX2 cell medium (Figure 8B).

To assess whether TSG-6 directly influenced liver restoration in mice with $\mathrm{CCl}_{4}$ damage, TSG-6-CM neutralized with TSG- 6 antibody was injected in $\mathrm{CCl}_{4}$-treated mice (TSG- $6+\mathrm{Ab}$ group) (Figure 1B). The livers of the TSG- 6 + Ab group had severe hepatic injuries, whereas the livers from the TSG-6 or TSG-6 + IgG groups showed almost normal morphology without distinct morphological differences between the two groups, as examined by $\mathrm{H}$ \& E staining (Figure 9A). The ratio of liver weight/ body weight (LW/BW) decreased and serum AST and ALT increased in mice in the TSG- 6 + Ab group, compared with mice in the TSG- 6 or TSG-6 + IgG group (Figure 9B, C, D). The RNA expression of g6pc was also down-regulated in the TSG-6 + Ab group (Figure 9E). Furthermore, the neutralization of TSG- 6 by TSG- 6 antibody led to an increase in the fibrotic markers, tgf- $\beta, \alpha$-sma and collagen $\alpha 1$, as assessed by quantitative real-time PCR (Figure 9F). In addition, the expression of inflammation markers, tnf- $\alpha$, il- $1 \beta$, cxcl1 and cxcl2, was higher in the TSG- 6 neutralized group than in the TSG-6 or TSG- 6 + IgG groups. Taken together, these data suggested that TSG-6 induced the inactivation of hepatic stellate cells, contributing to the ameliorated fibrosis in mice.

\section{Discussion}

Acute liver failure shows a higher inflammatory response to liver damage, which impairs the parenchymal function that extends into systemic organ failure, eventually leading to death $[16,31]$. Thus, researchers must develop new treatments for acute liver disease. The potential for MSCs to differentiate into hepatocytes and their immunomodulatory capabilities make MSCs an attractive choice in the therapy of acute or chronic liver diseases [9]. Several clinical trials are currently being performed to investigate the therapeutic potential of MSCs in the treatment of chronic liver diseases, such as Hepatitis B or C virus-infected liver or alcoholic liver with cirrhosis [32-34]. Previous studies have shown that transplanted MSCs replace the damaged cells and repopulate in the injured tissues or organs [35]. However, the number of long-term substituted MSCs is open to dispute because those numbers differed depending on the injury models, the transplant route and time, and so on [8]. Nevertheless, it seems to be uncontroversial that MSCs and the CM from MSCs contribute to improving damage from liver injuries $[9,36]$. The transplanted MSCs help or allow the survival or proliferation of endogenous cells by direct contact or modulating inflammation [9]. MSCs are known to alleviate acute and chronic liver injury by changing the disease environment; for example, they decreased inflammation and cell death, but they increased cell proliferation [9]. In the present study, TSG-6 released by MSCs suppressed the proinflammatory signal and reduced the collagen accumulation which was likely due to the inactivation of hepatic stellate cells by TSG-6 in the acute liver injury of mice.

Although the anti-inflammatory action of TSG-6 is shown to promote improvement in the damaged tissue $[14,37]$, this effect of TSG-6 in the liver remains unknown. Thus, we investigated whether TSG- 6 might be involved in 
A

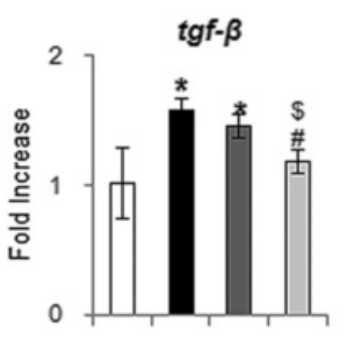

B

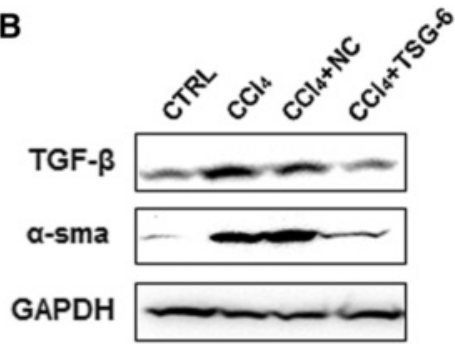

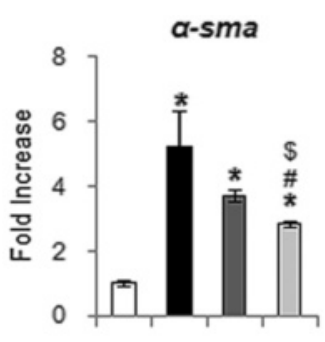

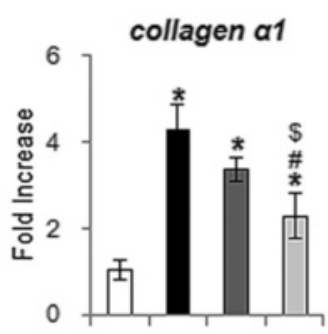

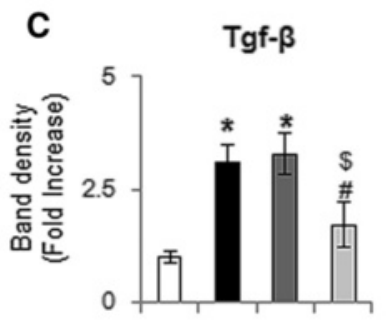

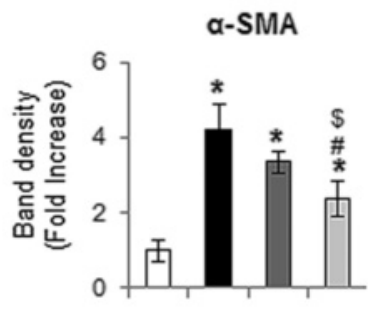

$\square \mathrm{CTRL}$

$\square \mathrm{CCl}_{4}+\mathrm{NC}$ $\square \mathrm{CCl}_{4}+\mathrm{TSG}-6$
*: vs CTRL
\#: vs $\mathrm{CCl}_{4}$
\$: vs $\mathrm{CCl}_{4}+\mathrm{NC}$

D
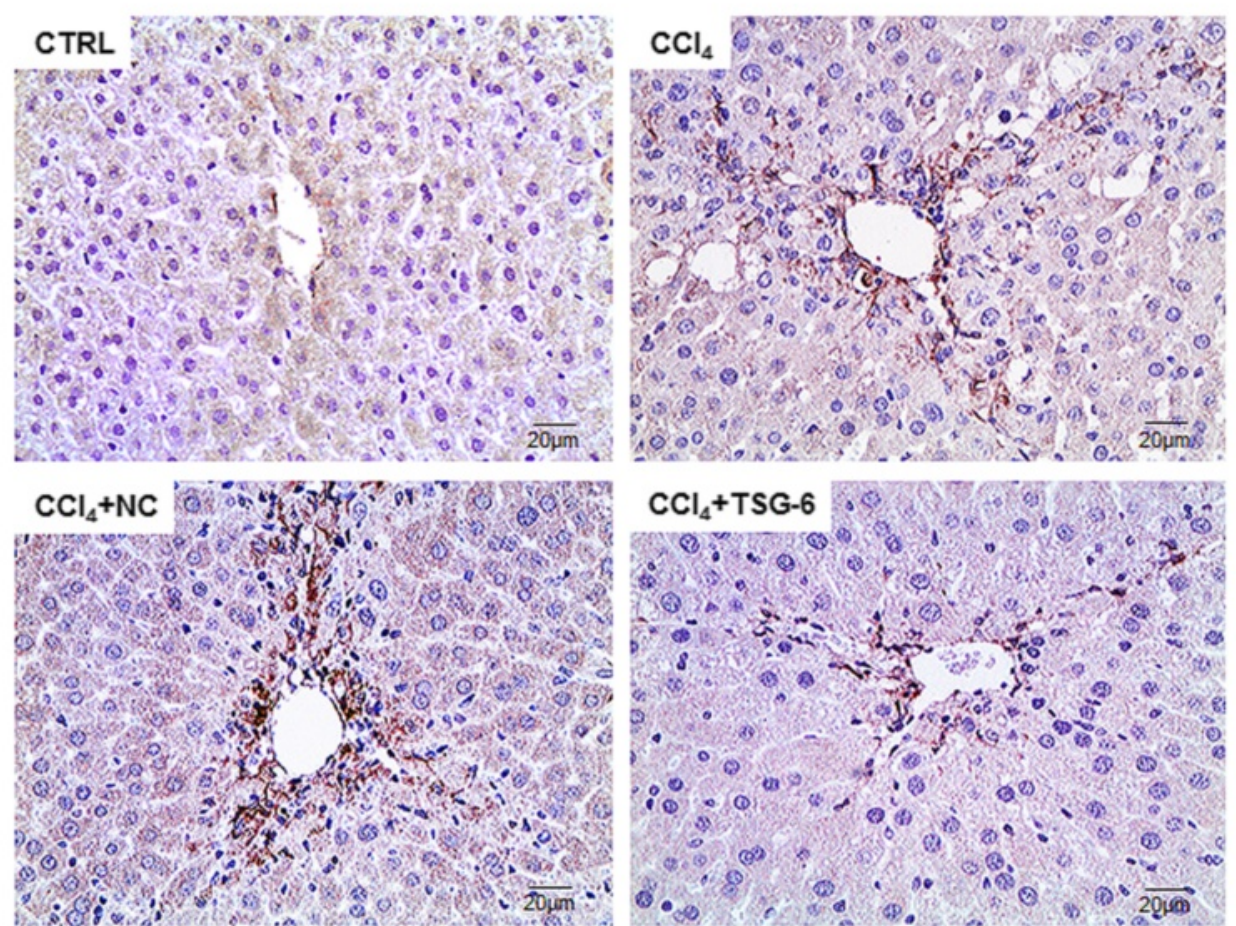

Figure 7 Reduced fibrosis in the TSG-6 treated liver. (A) QRT-PCR analysis of liver mRNA for tgf- $\beta$, $a-$ sma and collagen- $\alpha 1$ ( $n \geq 4$ mice/group). Mean \pm SD results are graphed. (B) and (C). Western blot analysis of TGF- $\beta$ ( $25 \mathrm{kDa}$ : processed form) (inducer of fibrosis) and a-SMA (fibrogenic marker) (GAPDH was used as an internal control) ( $n \geq 4$ mice/group). Data shown represent one of three experiments with similar results (B: Immunoblot/ C: Band density of TGF- $\beta$ and a-SMA). Data represent the mean $\pm \mathrm{SD}$ of three independent experiments. (D) $\mathrm{HC}$ for a-SMA in liver sections from representative $\mathrm{Control}_{1}, \mathrm{CCl}_{4}, \mathrm{CCl}_{4}+$ $\mathrm{NC}$, and $C C \mathrm{l}_{4}+\mathrm{TSG}-6$ mice $(\times 40)$ (ANOVA, ${ }^{*} P<0.05$ versus $C T R L, \# P<0.05$ versus $C C \mathrm{l}_{4}, \$ P<0.05$ versus $C \mathrm{Cl}_{4}+\mathrm{NC}-\mathrm{CM}$ ). ANOVA, analysis of variance; $C M$, conditioned medium; CTRL, control; IHC, immunohistochemistry; NC, negative control; SD, standard deviation; TSG-6, tumor necrosis factor-inducible gene 6 protein. 

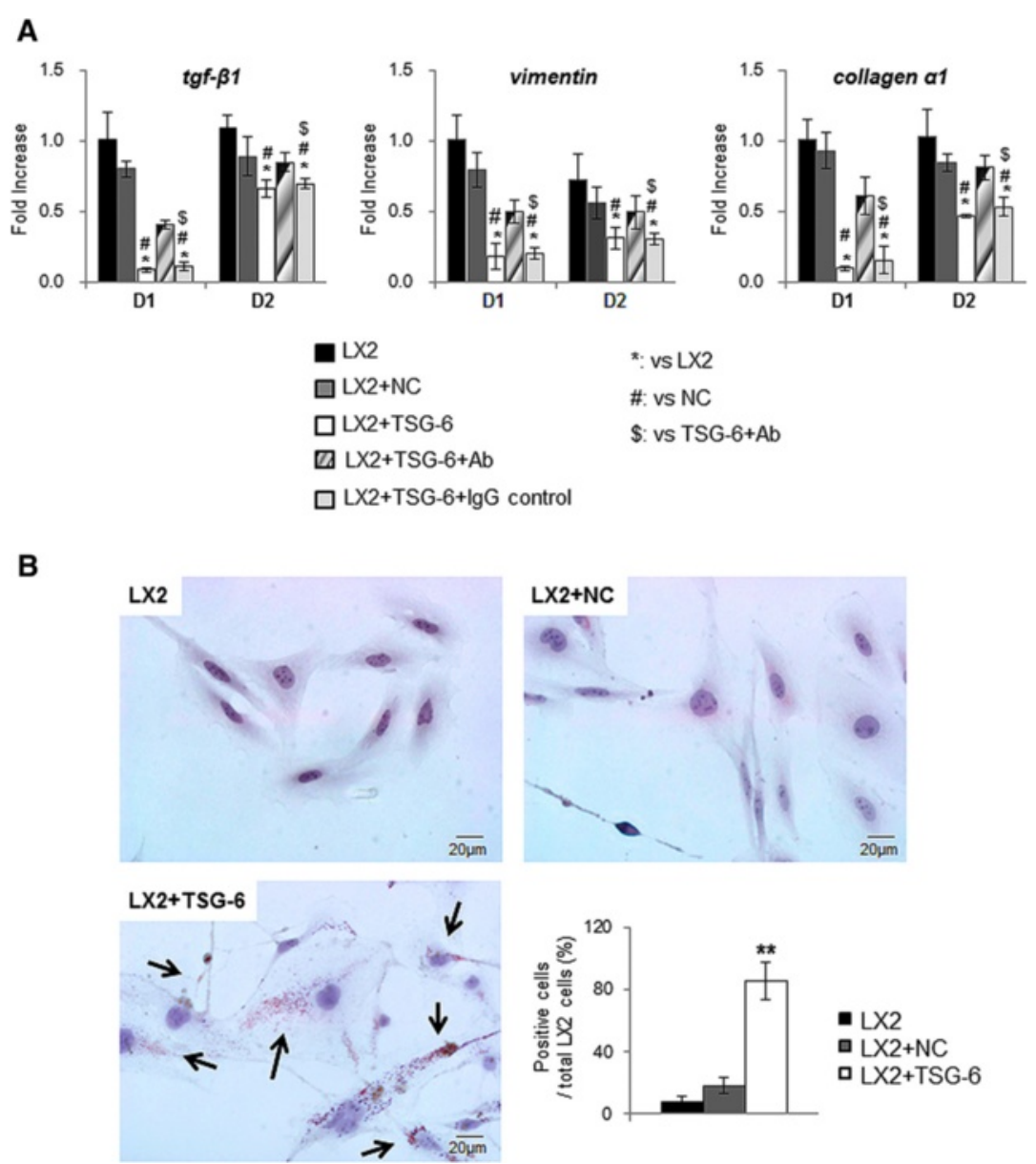

Figure 8 TSG-6 blocks activation of hepatic stellate cells. (A) QRT-PCR analysis for tgf- $\beta$, vimentin and collagen- $\alpha 1$ in LX2 cells which were cultured in LX2 cell medium (LX2), NC-CM (LX2 + NC), TSG-6-CM with (LX2 + TSG-6 + Ab) or without TSG-6 antibody (LX2 + TSG-6). IgG was used as a negative control for TSG-6 antibody ( $L X 2+T S G-6+\lg G)$. Mean \pm SD results are graphed. Data represent the mean \pm SD of three independent experiments (ANOVA, ${ }^{*} P<0.05$ versus $L X 2, \# P<0.05$ versus $N C, \$ P<0.05$ versus TSG- $6+A b$ ). (B) Oil Red $O$ staining in $L X 2$ cells cultured in $L X 2$, NC-CM, or TSG-6-CM (original magnification $\times 40$ ). ANOVA, analysis of variance; CM conditioned medium; lgG, immunoglobulin G; NC, negative control; SD, standard deviation; TSG-6, tumor necrosis factor-inducible gene 6 protein.

liver regeneration, and how it contributed to this process. Our results demonstrated that TSG-containing CM led to liver regeneration. This protective effect of TSG-6 was also observed in another experimental model; specifically, chorionic plate-derived MSCs (CP-MSCs) that shared common characteristics and differentiation potentials with bone marrow-MSCs promoted liver regeneration in rat livers that had been chronically damaged by $\mathrm{CCl}_{4}[38,39]$. In this model, the CP-MSCs contained a greater expression of TSG-6, and the regenerating liver transplanted with CPMSC showed a higher expression of TSG-6, compared to a non-transplanted liver (Additional file 1: Figure S1). This evidence strongly supported the regenerative effect of TSG6 in the liver.

In this experimental model, acutely injured livers showed distorted histomorphology, changes in LW/BW, and increased levels of the liver enzymes, ALT and AST, but TSG6-CM treatment attenuated those abnormalities and even contributed to restoring the liver function which was evidenced by g6pc expression. G6pc hydrolyzes glucose-6phosphate, which is the central metabolite of glucose metabolism [40]. The data showing almost normal glucose metabolic homeostasis in TSG-6-CM treated livers strongly support the restoration of liver function through the action of TSG-6. In addition, the downregulated proinflammatory factors in the TSG-6-CM group demonstrated that TSG-6 exerted an anti-inflammatory effect on the $\mathrm{CCl}_{4}$-treated mouse livers.

Liver injury induces activation of hepatic stellate cells and proliferation of progenitors $[16,26]$. Activated stellate cells have been shown to be associated with the proliferation of hepatic progenitors [27,41]. In Ki67 staining, more Ki67positive hepatocytic cells and fewer Ki67-positive hepatic stellate cells were observed in livers of the TSG6 group. Compared with liver of CCl4 + TSG-6-treated mice, livers of $\mathrm{CCl} 4$ or $\mathrm{CCl} 4+\mathrm{NC}$-treated mice contained more PanCK- 

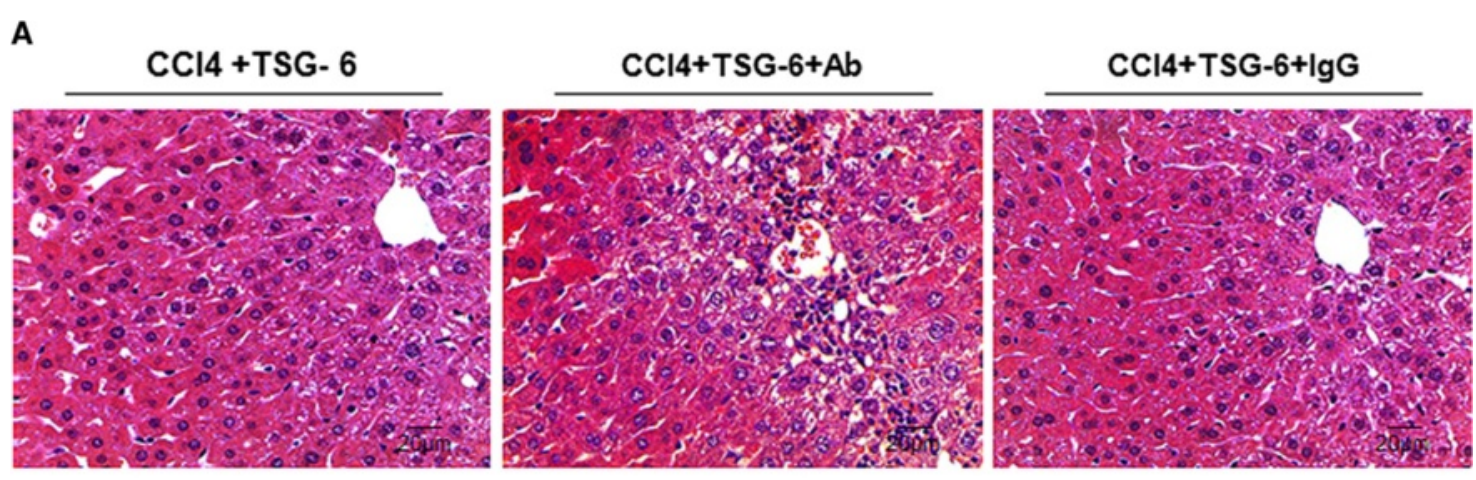

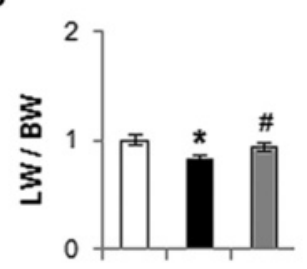

$\mathbf{F}$

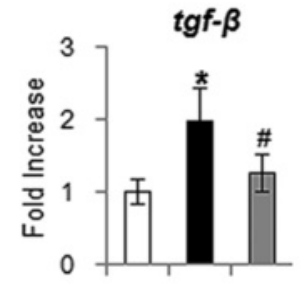

G

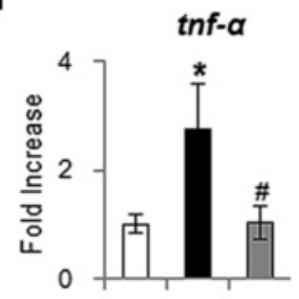

C

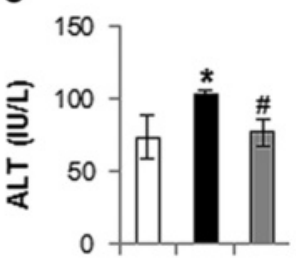

D

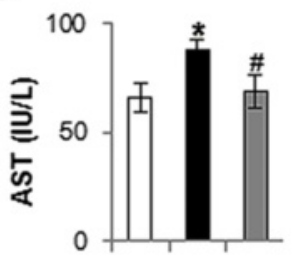

E

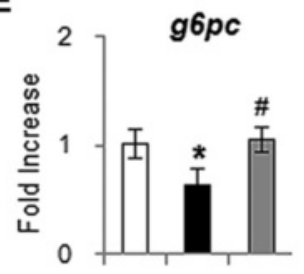

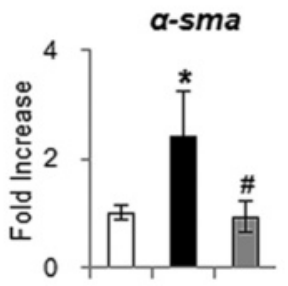
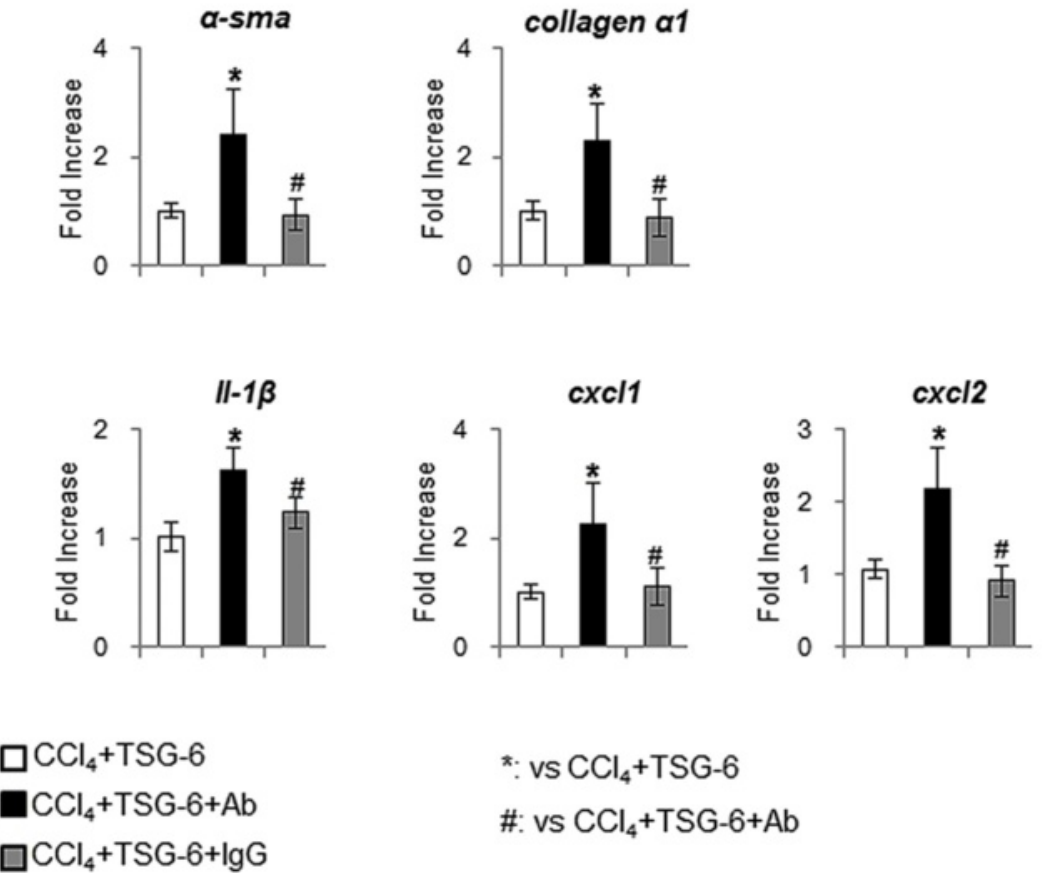

$$
\begin{aligned}
& \text { *: vs } \mathrm{CCl}_{4}+\mathrm{TSG}-6 \\
& \text { \#: vs } \mathrm{CCl}_{4}+\mathrm{TSG}-6+\mathrm{Ab}
\end{aligned}
$$

Figure 9 Neutralization of TSG- 6 by TSG- 6 antibody attenuates the restoration effect of TSG-6 in liver of $\mathrm{CCl}_{4}+\mathrm{TSG}^{-6-t r e a t e d ~ m i c e . ~(A) ~ H ~ \& ~ E ~}$ staining shows the histomorphological changes in CCl + TSG-6-treated mice with (CCl 4 + TSG-6 + TSG-6 antibody) (CCl + TSG-6 + lgG) without TSG-6 antibody (CCl + TSG-6) or lgG. The representative images were shown at $\times 40$. (B) Relative liver weight/body weight of mice. (C), (D) The values of AST and ALT are graphed. (E, F, G) QRT-PCR analysis for G6pc (E), the fibrotic markers (F), tgf- $\beta$, a-sma and collagen-a1, the inflammation markers (G), tnfa, il-1 13 , cxcl1 and $\mathrm{cxcl} 2$, of liver mRNA from the treated mice ( $\mathrm{n} \geq 4$ mice / group). Mean \pm SD results are graphed (ANOVA, ${ }^{*} P<0.05$ versus TSG-6, \#P<0.05 versus TSG- $6+$ Ab). ALT, alanine aminotransferase; ANOVA, analysis of variance; AST, aspartate aminogransferase; G6pc, glucose-6-phosphatase; lgG, immunoglobulin G; SD, standard deviation; TSG-6, tumor necrosis factor-inducible gene 6 protein. 
expressing cells and more SoX9-expressing cells (Figure 5). We examined if these changes in the activation and /or proliferation of hepatic stellate cells and the reduced liver damage influenced the proliferation of progenitors. As we expected, decreased expansion of progenitors was observed in livers of the TSG- 6 group, compared to the $\mathrm{CCl} 4$ and $\mathrm{NC}$ groups. Therefore, these results indicated that micro-environmental changes by TSG-6 might contribute to the proliferation of hepatocytes by protecting hepatocytes from injury. Also, it could be possible that TSG-6 might promote differentiation of progenitors into hepatocytes. However, neither the direct effects of TSG-6 on progenitors nor the progenitor proliferation at the early time point after $\mathrm{CM}$ injection was investigated in the present studies. Hence, further studies are required to provide the evidence for this possibility.

The degree of inflammatory response parallels the fibrotic severity in the liver [42]. The activated hepatic stellate cells play a key role in hepatic fibrogenesis $[43,44]$. Both RNA and the protein level of fibrotic markers were downregulated in the livers of TSG-6CM-treated mice. Activated LX2 cultured in TSG-6-CM showed a decreased expression of fibrotic markers and an increased number of lipid drops. Conversely, the addition of the TSG- 6 antibody neutralized these inhibitory effects of TSG-6 on the activation of LX2, although this addition was less effective than NC-CM. It is possible that the TSG-6 antibody does not block all TSG-6, and the amount of TSG- 6 that escaped blocking by the antibody is higher than it is in NC-CM. One explanation is that the TSG-6-overexpressing MSCs and the CM of those cells show a greater expression of TSG-6, but TSG- 6 is rarely detected in NC and NC-CM. Hence, these results proved that TSG- 6 influenced the activation of hepatic stellate cells, suggesting that TSG- 6 contributed to the reduced fibrosis in damaged livers of mice.

CM obtained from empty plasmid-transfected MSC was less protective in the damaged liver. In line with our finding, Herrera et al. [7], demonstrated that both human liver stem cells (HLSCs) and HLSC-CM improved liver injury and had a protective effect for liver, but MSC-CM was totally ineffective in their experimental model [7]. In addition, they employed the concentrated $\mathrm{CM}$ in their experimental model of liver injury, like other researchers did. However, the CM used in the present studies was not concentrated. MSC-CM includes many kinds of cytokines, growth factors, and even microparticles [37,45]. Because we used $0.5 \mathrm{ml} \mathrm{CM}$ per mouse from a total $12 \mathrm{ml} \mathrm{CM}$ which was collected at 70\% to $80 \%$ confluent cells, this small volume of CM seemed to contain a significantly lower amount of those factors, compared to the concentrated CM. Hence, the effects of other factors were likely negligible in this model. Also, we examined the regulation of hepatic stellate cells by TSG-6, not the apoptosis of hepatocytes, and demonstrated that hepatic stellate cells were inactivated in TSG-6-CM, but not in NCCM or TSG-6-CM with the TSG-6 antibody. Furthermore, $\mathrm{CCl}_{4}$-treated mice injected with TSG-6-CM incubated with TSG-6 antibody induced the liver damage which was ameliorated in $\mathrm{CCl}_{4}$-treated mice with TSG-6-CM. These results suggest that the reduced inflammation and fibrosis caused by TSG- 6 might provide a beneficial microenvironment which contributes to the proliferation or survival of hepatocytes, leading to liver regeneration.

\section{Conclusions}

Our results first demonstrate that TSG-6 influences liver regeneration and place TSG- 6 into the central position in the regulation of liver regeneration. The protective and/or improving effects of TSG-6 on the damaged liver through attenuating inflammation and fibrosis help to develop novel therapeutic approaches to treat acute liver failure. However, further studies are required to examine the underlying mechanism for the regenerative actions of TSG- 6 and those effects in other liver diseases, including chronic diseases.

\section{Additional file}

Additional file 1: Figure S1. Chorionic plate-derived MSCs express TSG-6. (A) QRT-PCR analysis for TSG-6 in CP-MSCs (B) QRT-PCR analysis for CP-MSCs-transplanted rat liver which had been chronically damaged by CCl4 $\left.{ }^{*} P<0.05,{ }^{* *} P<0.005\right)$ (Transplantation: $C C l_{4}$-treated rats with CP-MSCs transplantation).

\section{Abbreviations}

ALT: alanine aminotransferase; ANOVA: analysis of variance; AST: aspartate aminotransferase; CFSE: carboxyfluorescein succinimidyl ester; CM: conditioned medium; FBS: fetal bovine serum; G6pc: glucose-6phosphatase; H \& E: hematoxylin and eosin; hMSC: human mesenchymal stem/stromal cells; IHC: immunohistochemistry; IL: interleukin; NC: negative control; PanCK: pancytokeratin; PBS: phosphage-buffered saline; SD: standard deviation; TGF- $\beta$ : transforming growth factor- $\beta$; TNF-a: tumor necrosis factor-a; TSG-6: tumor necrosis factor-inducible gene 6 protein; $a-S M A$ : a-smooth muscle actin.

\section{Competing interests}

The authors declare that they have no competing interests.

\section{Authors' contributions}

SW performed the animal, cell culture and molecular experiments, analyzed the data, and drafted the manuscript. JSL and SK carried out the immune suppression assay. $\mathrm{JH}$ and $\mathrm{JK}$ participated in the cell culture experiments and help to ORO staining imaging. $\mathrm{HJC}$ and $\mathrm{YJ}$ conceived and designed the study and analyzed the data. YJ contributed reagents/materials/analysis tools and helped to draft the manuscript. All authors read and approved the final manuscript

\section{Acknowledgments}

The authors thank Dr. Gi Jin Kim (Cha University, Korea) for providing the CP-MSC and rat liver tissue. This work was supported by the National Research Foundation (NRF) of Korea funded by the Korean government (MEST) (2013R1A2A2A01068268) to YJ.

\section{Author details}

'Department of Intergrated Biological Science, Pusan National University, 63-2 Pusandaehak-ro, Kumjeong-gu, Pusan 609-735, Korea. ${ }^{2}$ Department of Biological Sciences, Pusan National University, 63-2 Pusandaehak-ro, Kumjeong-gu, Pusan 609-735, Korea. ${ }^{3}$ Department of Life Science, Sogang 
University, Seoul 121-742, Korea. ${ }^{4}$ Division of Neurology, Department of Medicine, University of British Columbia, Vancouver, BC, Canada.

Received: 11 December 2014 Revised: 16 February 2015 Accepted: 24 February 2015 Published online: 11 March 2015

\section{References}

1. Foley DP, Fernandez LA, Leverson G, Anderson M, Mezrich J, Sollinger HW, et al. Biliary complications after liver transplantation from donation after cardiac death donors: an analysis of risk factors and long-term outcomes from a single center. Ann Surg. 2011;253:817-25.

2. Zhang Z, Wang FS. Stem cell therapies for liver failure and cirrhosis. J Hepatol. 2013;59:183-5.

3. Aurich I, Mueller LP, Aurich H, Luetzkendorf J, Tisljar K, Dollinger MM, et al. Functional integration of hepatocytes derived from human mesenchymal stem cells into mouse livers. Gut. 2007:56:405-15.

4. Sgodda M, Aurich H, Kleist S, Aurich I, Konig S, Dollinger MM, et al. Hepatocyte differentiation of mesenchymal stem cells from rat peritoneal adipose tissue in vitro and in vivo. Exp Cell Res. 2007;313:2875-86.

5. Christ B, Stock P. Mesenchymal stem cell-derived hepatocytes for functional liver replacement. Front Immunol. 2012;3:168.

6. Parekkadan B, van Poll D, Suganuma K, Carter EA, Berthiaume F, Tilles AW, et al. Mesenchymal stem cell-derived molecules reverse fulminant hepatic failure. PLoS One. 2007;2:e941.

7. Herrera MB, Fonsato V, Bruno S, Grange C, Gilbo N, Romagnoli R, et al. Human liver stem cells improve liver injury in a model of fulminant liver failure. Hepatology. 2013;57:311-9.

8. Meier RP, Muller YD, Morel P, Gonelle-Gispert C, Buhler LH. Transplantation of mesenchymal stem cells for the treatment of liver diseases, is there enough evidence? Stem Cell Res. 2013;11:1348-64.

9. Volarevic V, Nurkovic J, Arsenijevic N, Stojkovic M. Concise review: therapeutic potential of mesenchymal stem cells for the treatment of acute liver failure and cirrhosis. Stem Cells. 2014;32:2818-23.

10. Lee JW, Fang X, Krasnodembskaya A, Howard JP, Matthay MA. Concise review: mesenchymal stem cells for acute lung injury: role of paracrine soluble factors. Stem Cells. 2011;29:913-9.

11. Song SH, Lee MO, Lee JS, Jeong HC, Kim HG, Kim WS, et al. Genetic modification of human adipose-derived stem cells for promoting wound healing. J Dermatol Sci. 2012;66:98-107.

12. Tsukahara S, Ikeda R, Goto S, Yoshida K, Mitsumori R, Sakamoto Y, et al. Tumour necrosis factor alpha-stimulated gene-6 inhibits osteoblastic differentiation of human mesenchymal stem cells induced by osteogenic differentiation medium and BMP-2. Biochem J. 2006:398:595-603.

13. Milner CM, Day AJ. TSG-6: a multifunctional protein associated with inflammation. J Cell Sci. 2003;116:1863-73.

14. Prockop DJ, Oh JY. Mesenchymal stem/stromal cells (MSCs): role as guardians of inflammation. Mol Ther. 2012;20:14-20.

15. Syn WK, Oo YH, Pereira TA, Karaca GF, Jung Y, Omenetti $A$, et al, Accumulation of natural killer $T$ cells in progressive nonalcoholic fatty liver disease. Hepatology. 2010;51:1998-2007.

16. Bataller R, Brenner DA. Liver fibrosis. J Clin Invest. 2005;115:209-18.

17. Syn WK, Agboola KM, Swiderska M, Michelotti GA, Liaskou E, Pang H, et al. NKT-associated hedgehog and osteopontin drive fibrogenesis in non-alcoholic fatty liver disease. Gut. 2012;61:1323-9.

18. De Minicis S, Svegliati-Baroni G. Fibrogenesis in nonalcoholic steatohepatitis. Expert Rev Gastroenterol Hepatol. 2011;5:179-87.

19. Fujii H, Kawada N. Inflammation and fibrogenesis in steatohepatitis. J Gastroenterol. 2012:47:215-25.

20. Lee JS, Lee MO, Moon BH, Shim SH, Fornace AJ, Cha HJ. Senescent growth arrest in mesenchymal stem cells is bypassed by Wip1-mediated downregulation of intrinsic stress signaling pathways. Stem Cells. 2009;27:1963-75.

21. Nagai A, Kim WK, Lee HJ, Jeong HS, Kim KS, Hong SH, et al. Multilineage potential of stable human mesenchymal stem cell line derived from fetal marrow. Plos One. 2007;2:e1272.

22. Lowe JM, Cha H, Yang Q, Fornace Jr AJ. Nuclear factor-kappaB (NF-kappaB) is a novel positive transcriptional regulator of the oncogenic Wip1 phosphatase. J Biol Chem. 2010;285:5249-57.

23. Datta S, Basu K, Sinha S, Bhattacharyya P. Hepatoprotective effect of a protein isolated from Cajanus indicus (Spreng) on carbon tetrachloride induced hepatotoxicity in mice. Indian J Exp Biol. 1998;36:175-81.
24. Xu L, Hui AY, Albanis E, Arthur MJ, O'Byrne SM, Blaner WS, et al. Human hepatic stellate cell lines, LX-1 and LX-2: new tools for analysis of hepatic fibrosis. Gut. 2005;54:142-51.

25. Omenetti A, Porrello A, Jung Y, Yang L, Popov Y, Choi SS, et al. Hedgehog signaling regulates epithelial-mesenchymal transition during biliary fibrosis in rodents and humans. J Clin Invest. 2008;118:3331-42.

26. Jung Y, Witek RP, Syn WK, Choi SS, Omenetti A, Premont R, et al. Signals from dying hepatocytes trigger growth of liver progenitors. Gut. 2010;59:655-65.

27. Jung Y, Yang L, Omenetti A, Witek RP, Choi S, Vandongen HM, et al. Fate-mapping evidence that hepatic stellate cells are epithelial progenitors in adult mouse livers. Stem Cells. 2008;26:2104-13.

28. Fausto $\mathrm{N}$. Involvement of the innate immune system in liver regeneration and injury. J Hepatol. 2006:45:347-9.

29. Wang $S$, Lee K, Hyun J, Lee $Y$, Kim Y, Jung Y. Hedgehog signaling influences gender-specific response of liver to radiation in mice. Hepatol Int. 2013;7:1065-74

30. Dorrell C, Erker L, Schug J, Kopp JL, Canaday PS, Fox AJ, et al. Prospective isolation of a bipotential clonogenic liver progenitor cell in adult mice. Genes Dev. 2011;25:1193-203.

31. Rolando N, Wade J, Davalos M, Wendon J, Philpott-Howard J, Williams R. The systemic inflammatory response syndrome in acute liver failure. Hepatology. 2000;32:734-9

32. El-Ansary M, Abdel-Aziz I, Mogawer S, Abdel-Hamid S, Hammam O, Teaema S, et al. Phase II trial: undifferentiated versus differentiated autologous mesenchymal stem cells transplantation in Egyptian patients with HCV induced liver cirrhosis. Stem Cell Rev. 2012;8:972-81.

33. Wang HM, Hung $\mathrm{CH}$, Lu SN, Chen $\mathrm{CH}$, Lee $\mathrm{CM}$, Hu TH, et al. Liver stiffness measurement as an alternative to fibrotic stage in risk assessment of hepatocellular carcinoma incidence for chronic hepatitis C patients. Liver Int. 2013;33:756-61.

34. Amin MA, Sabry D, Rashed LA, Aref WM, el-Ghobary MA, Farhan MS, et al. Short-term evaluation of autologous transplantation of bone marrow-derived mesenchymal stem cells in patients with cirrhosis: Egyptian study. Clin Transplant. 2013;27:607-12.

35. Wu XB, Tao R. Hepatocyte differentiation of mesenchymal stem cells. Hepatobiliary Pancreat Dis Int. 2012;11:360-71.

36. Rashid T, Takebe T, Nakauchi H. Novel strategies for liver therapy using stem cells. Gut. 2015;64:1-4.

37. Wang N, Li Q, Zhang L, Lin H, Hu J, Li D, et al. Mesenchymal stem cells attenuate peritoneal injury through secretion of TSG-6. PLoS One. 2012;7:e43768.

38. Lee MJ, Jung J, Na KH, Moon JS, Lee HJ, Kim JH, et al. Anti-fibrotic effect of chorionic plate-derived mesenchymal stem cells isolated from human placenta in a rat model of CCl(4)-injured liver: potential application to the treatment of hepatic diseases. J Cell Biochem. 2010;111:1453-63.

39. Jung J, Choi JH, Lee Y, Park JW, Oh $\mathbb{H}$, Hwang SG, et al. Human placenta-derived mesenchymal stem cells promote hepatic regeneration in CCl4 -injured rat liver model via increased autophagic mechanism. Stem Cells. 2013;31:1584-96.

40. Ghafoory S, Breitkopf-Heinlein K, Li Q, Scholl C, Dooley S, Wolfl S. Zonation of nitrogen and glucose metabolism gene expression upon acute liver damage in mouse. PLoS One. 2013:8:e78262.

41. Choi SS, Omenetti A, Syn WK, Diehl AM. The role of Hedgehog signaling in fibrogenic liver repair. Int J Biochem Cell Biol. 2011;43:238-44.

42. Tsui TY, Lau CK, Ma J, Wu X, Wang YQ, Farkas S, et al. rAAV-mediated stable expression of heme oxygenase-1 in stellate cells: a new approach to attenuate liver fibrosis in rats. Hepatology. 2005;42:335-42.

43. Wang S, Lee Y, Kim J, Hyun J, Lee K, Kim Y, et al. Potential role of Hedgehog pathway in liver response to radiation. PLoS One. 2013:8:e74141.

44. Hyun J, Choi SS, Diehl AM, Jung Y. Potential role of Hedgehog signaling and microRNA-29 in liver fibrosis of IKKbeta-deficient mouse. J Mol Histol. 2014:45:103-12

45. Lee RH, Pulin AA, Seo MJ, Kota DJ, Ylostalo J, Larson BL, et al. Intravenous hMSCs improve myocardial infarction in mice because cells embolized in lung are activated to secrete the anti-inflammatory protein TSG-6. Cell Stem Cell. 2009:5:54-63. 